\title{
The relationship between children's flourishing and being overweight
}

\author{
Tae Eung Kim', Chang-Yong Jang ${ }^{2, *}$ \\ 'Department of Applied Health Science, Indiana University, Bloomington, IN, USA \\ ${ }^{2}$ Institute of Sport Science, College of Arts and Physical Education, Incheon National University, Incheon, Korea
}

This study examined the effect of children's flourishing on the pandemic of obesity from various aspects such as age, gender, race, family, school, and community. By using a subsample of the 2011-2012 National Survey of Children's Health, the Flourishing scale analyses were performed with a total of 45,309 children. Childhood obesity was diagnosed by calculating the percentile of the body mass index. Hispanic Americans were more likely to be overweight $(P<0.01)$. Nonoverweight children were more likely to participate in after-school activities, less likely to have sedentary behavior, more likely to miss school, to be more active, and had more of flourishing than their counterpart $(P<0.01)$. Par- ent's marital and health status also positively affect children's obesity status $(P<0.01)$. Social capital and neighbor amenities significantly affect children's weight status $(P<0.01)$. A multifaceted understanding of the role of family, school, and community (with proving children's flourishing environment) in terms of how and what could contribute to children's obesity status is important in order to bring about positive impact.

Keywords: Obesity, Well-being, Socioecological factors, Individual factors, Parenting capacity

\section{INTRODUCTION}

Childhood obesity rates have increased by more than 4 times over the last 30 years in the United States (Ogden et al., 2014). Childhood obesity is linked to poor mental health and well-being, and to an increased risk of developing obesity in later adulthood (Guo and Chumlea, 1999). In addition, it is associated with a higher risk for heart disease, type 2 diabetes, stroke, and osteoarthritis (Benjamin, 2010). Childhood obesity not only causes physical health issues (Benjamin, 2010; Li et al., 2009), but also exacerbates mental and psychological health problems among children and young adults (Guo and Chumlea, 1999; Russell-Mayhew et al., 2012).

Childhood obesity-related factors have been well established and are highly associated with socioecological settings. Flourishing is a new concept of one's happiness and well-being (De Ruyter, 2007; Seligman, 2011), children's flourishing is substantially related to the influence of parents, family, and the environment
(Cleaver and Walker, 2004; Davison and Birch, 2001). It is wellestablished that childhood obesity is usually caused by a combination of poor lifestyle habits such as high calorie intake, a lack of physical activity, and a sedentary lifestyle (Benjamin, 2010). These poor lifestyle patterns are typically attributed to the family (Gibson et al., 2013), school (Williams et al., 2013), one's community (Bleich et al., 2013), and one's environment (Zhao and Settles, 2014). According to Must et al. (2014), family, school, and the community play a key role in preventing and minimizing children's obesity. There is a need to establish healthy and positive environments with polices and initiatives that provide opportunities for children to learn, practice healthy eating, and become physically active.

Childhood is a vital period for the development of necessary behaviors that contribute to health in later life, including managing a healthy weight, being active, minimizing sedentary behaviors, and developing healthy eating habits (e.g., consuming fruit and vegetables, consuming lower fat foods, and avoiding junk foods)
${ }^{*}$ Corresponding author: Chang-Yong Jang (D https://orcid.org/0000-0002-6650-6253 Institute of Sport Science, College of Arts and Physical Education, Incheon National University, 119 Academy-ro, Yeonsu-gu, Incheon 22012, Korea Tel: +82-32-835-4235, Fax: +82-32-835-0789, E-mail: ericjang529@gmail.com Received: April 10, 2018 / Accepted: July 14, 2018
This is an Open Access article distributed under the terms of the Creative Commons Attribution Non-Commercial License (http://creativecommons.org/licenses/by-nc/4.0/) which permits unrestricted non-commercial use, distribution, and reproduction in any medium, provided the original work is properly cited. 
(U.S. Department of Health \& Human Services, 2010). Moreover, the transition from adolescence to young adulthood represents a critical developmental stage that substantially affects lifelong healthy behaviors. Poor health behaviors or practices adopted during the initial stages of development are hard to change and contribute to decrease in quality of life in late adulthood (U.S. Department of Health \& Human Services, 2010).

Based on these situations, this study reflected a modified social ecological model (Bronfenbrenner, 1994) as the conceptual framework. According to the model, children are significant transitions in their lives. This model provides a systematic way of analyzing, understanding, and recording what is going on in children's lives and where they exist. The framework consisted of three parts, children's individual needs (i.e., emotional and behavioral development, identity, family, and social relationships), parenting capacity (i.e., emotional warmth, stimulation, guidance, and boundaries), and family and environmental factors (i.e., family's social integration, income, and family history). Children are nested within parents, family, and environmental factors, which means a multilevel research approach is needed to account for key implications in a hierarchical structure (Bronfenbrenner, 1994). This approach includes the significant roles of children, parents, family, and community members in association with childhood development.

The specific objective of this study was to understand the roles of family, school, and the community in children's obesity and if children's flourishing, among other socioecological factors, can help prevent this pandemic. A secondary objective was to examine age, sex, and race/ethnicity differences in overweight children's flourishing.

\section{MATERIALS AND METHODS}

\section{Data and study population}

This study used a subsample from the 2011-2012 National Survey of Children's Health (NSCH), which was sponsored and funded by the Maternal and Child Health Bureau of the Health Resources and Services Administration. Random sampling and telephone households interviews were performed by the National Center for Health Statistics of the Centers for Disease Control and Prevention (Centers for Disease Control and Prevention [CDC], 2013). The NSCH is weighted to represent the population of non-institutionalized children aged $0-17$ years nationally and provided information on a variety of physical, emotional, and behavioral health indicators relating to children, their family, and neighborhoods. This study extracted data from children aged 10-
17 years for this study because this study did not obtain obesity status information about children aged younger than 10. In total, 45,309 children (of 33,293,823 at the population level) were identified (mean age, 13.63 years; girls, 48.72\%). The Institutional Review Board at Indiana University exempted this study.

\section{Measures}

Flourishing was measured with a 5 Point-Likert scale (1-5). The questions were the following: (a) (He/She) finishes the tasks (he/she) starts and follows through with what (he/she) says (he will/she will) do, (b) (He/She) stays calm and in control when faced with a challenge, and (c) (He/She) shows interest and curiosity in learning new things. The scale's internal consistency was good in this study $(\alpha=0.75)$.

BMI percentile was used to determine childhood obesity severity. Children's BMI was calculated as weight in kilograms divided by squared height in meters, while also considering the child's age and sex (CDC, 2009). Childhood obesity is defined as a combination of $85 \%$ and less than 95 percentile of BMI and greater than 95 percentile BMI with the consideration of age and sex, respectively (Krebs et al., 2007).

Sociological factors related to flourishing including family and parents' health behaviors such as using alcohol, smoking, family activity, and volunteering were also measured. Children's sex, race/ ethnicity, age, days of school missed, after-school activities, quality of sleep, physical activity, and sedentary behavior were measured. Missed school days was measured by the number of days because of illness or injury during the past year. A composite measure for after-school activity was computed by three binary scales including participation in any clubs/organizations, taking sports classes or being on a sports team, and taking part in any other organized activity during the past year. The sleep quality variable was assessed by how many nights the participant slept well during the previous week. Physical activity was measured by how many days a child exercises, played a sport, or participated in vigorous physical activity for at least $20 \mathrm{~min}$. Additionally, a composite scale score for sedentary behavior was used, calculated as the product of the length of activity time and the unit of measure (hr) for activities such as watching TV, videos, DVDs, or playing video games.

Parenting capacity included parents' involvement, parents' health, parents' stress coping, smoking, alcohol and drug use, and having a mentor. Parents' involvement was measured by a summation of 3 items: attending events or activities that their children participated in; how often their children have been involved 
in any type of community service or volunteer work at school, church, or in the community during the past year; and how many of their children's friends they have met. Parents' health was measured as the average of mothers' and the fathers' physical and mental health. Parents' stress coping was assessed with a 4-point Likert scale that addressed how well they feel they are coping with the daily needs of their children. Two binary items were used to measure parents' health behaviors: smoking and alcohol/drug use. Lastly, a binary item was used to ask if parents had a mentor who they can rely on for advice in the school, neighborhood, or community.

Family function consisted of family activity, parent and child relationship, number of family members aged $<18$ years, and federal poverty level (FPL). Family activity was assessed by a 2 -scale composite measure including how often children attended a religious service and how many days during the past week all the family members got together to eat. Parent and child relationship was assessed by a 4 Likert scale asking how well a parent(s) share ideas or talk about things that "really matter." A 4 Likert-scale item was used to measure the number of family members aged $<18$ years. A participant's FPL was categorized into four groups based: $0 \%-$ 99\%, 100\%-199\%, 200\%-399\%, and $\geq 400 \%$ (Blumberg et al., 2003).

Environmental factors consisted of a single parent variable, neighborhood amenities, social capital, and perceived safety around their current residence. Initially, there were nine categories of combined family structure and marital/cohabitation status of a child's parent(s); however, this study restructured those groups as a binary variable, such as single-parent vs. another family structure, because singleparent children's health status may differ from those who are from a different family structure. Neighborhood amenities was computed as a summation of three binary items, including whether sidewalks or walking paths existed, park or playground areas, and if there was a recreation or community center in their area. A composite score for social capital was calculated by respondents' answers to four continuous items: how much they agree that (a) people help each other out; (b) they watch out for each other's children; (c) there are people they can count on; and (d) if their children were outside playing and something happened, there are adults nearby who they trust to help their child. Perceived safety around their living conditions was computed as a summation of two items: how often they feel their child is safe in their community or neighborhood and at school.

\section{Statistical analyses}

Descriptive statistics of the population were reported to present the study sample's demographic characteristics such as age, sex, race, and weight with means, standard deviations, or percentages. A weighted sequential multivariable logistic regression (i.e., normal weight vs. overweight) was performed to capture the factors influencing children's weight, controlling for demographics, physical activity-related behaviors, and family and environment conditions. Additionally, this study used the product of coefficients procedure (Aiken et al., 1991) to determine if age, sex, and race/ ethnicity moderated any of these effects in each model. All statistical analyses were conducted using Stata 15.1 (StataCorp LP., College Station, TX, USA) and statistical tests were conducted using a 0.05 alpha level and a $95 \%$ confidence interval (CI).

\section{RESULTS}

Descriptive statistics of the study population are shown in Table 1. More than half were non-Hispanic white (56.67\%). Children who were Hispanic American were more likely than their counterparts to be overweight $(P<0.01)$. Nonoverweight children were more likely to participate in after-school activities, less likely to have sedentary behavior, more likely to miss school, to be more active, and flourished more than their counterparts did (all $P<0.01)$. However, sleep quality was not significant.

Regarding parenting capacity resources, the parent of nonoverweight children had better health than those who had overweight children $(P<0.01)$. In addition, parents with nonoverweight children were more likely to attend events or activities that their children participated in and were more likely to be involved in any type of community service or volunteer work at school, church, or in the community during the past year $(P<0.01)$. Moreover, parents of nonoverweight children were more likely to cope with their stress $(P<0.01)$, and were more likely to have mentors who can discuss their difficulties in caring for children and secure better alternative with any significant others than were parents of overweight children. On the other hand, overweight children's parents were more likely to smoke a cigarette and consume alco$\mathrm{hol} /$ drugs than their nonoverweight counterparts (all $P<0.01$ ).

Families with overweight children were significantly more likely to attend a religious service and more likely to have eaten together as a family during the past week. Children living in midand high-income families were less likely to be overweight that those who were from a low-income household. However, parent and child relationship $(P=0.53)$ and number of family members 
Table 1. Participants' descriptive statistics per their weight $(n=45,309$, weighted $n=33,293,823)$

\begin{tabular}{|c|c|c|c|c|}
\hline Variable & Overweight & Nonoverweight & Overall & $P$-value \\
\hline No. of participants & 12,788 (31.34) & $31,076(68.66)$ & $43,864(100)$ & \\
\hline \multicolumn{5}{|l|}{ Individual } \\
\hline Age (yr) & $13.14 \pm 2.25$ & $13.76 \pm 2.38$ & $13.53 \pm 2.35$ & $<0.01$ \\
\hline Female sex & $5,216(43.15)$ & $15,732(51.13)$ & 20,948 (48.63) & $<0.01$ \\
\hline Race/ethnicity & & & & $<0.01$ \\
\hline Non-Hispanic White & $7,674(47.58)$ & $22,218(60.82)$ & 29,892 (56.67) & \\
\hline Non-Hispanic Black & $1,759(19.40)$ & $2,370(12.42)$ & $4,129(14.61)$ & \\
\hline Hispanic & $1,756(24.61)$ & 2,921 (16.93) & 4,677 (19.33) & \\
\hline Other & $1,296(8.42)$ & $2,957(9.83)$ & 4,253 (9.39) & \\
\hline School missing (day) & $4.26 \pm 5.96$ & $3.75 \pm 5.35$ & $3.85 \pm 5.49$ & $<0.01$ \\
\hline After school activity (day) & $1.43 \pm 0.99$ & $1.65 \pm 0.99$ & $1.56 \pm 1.00$ & $<0.01$ \\
\hline Quality of sleeping (day) & $5.81 \pm 1.77$ & $5.80 \pm 1.80$ & $5.81 \pm 1.78$ & 0.87 \\
\hline Physical activity (day) & $4.01 \pm 2.26$ & $4.28 \pm 2.34$ & $4.15 \pm 2.32$ & $<0.01$ \\
\hline Sedentary behaviors (hr) & $4.44 \pm 3.50$ & $3.95 \pm 3.54$ & $4.04 \pm 3.51$ & $<0.01$ \\
\hline Flourishing & $4.10 \pm 0.69$ & $4.17 \pm 0.68$ & $4.15 \pm 0.69$ & $<0.01$ \\
\hline \multicolumn{5}{|l|}{ Parenting capacity } \\
\hline Parents health $\left({ }^{\circ}\right)$ & $6.28 \pm 2.38$ & $7.01 \pm 2.39$ & $6.75 \pm 2.40$ & $<0.01$ \\
\hline Parental involvement (frequency) & $8.13 \pm 2.38$ & $8.81 \pm 2.29$ & $8.51 \pm 2.38$ & $<0.01$ \\
\hline Parental stress coping $\left({ }^{\circ}\right)$ & $3.51 \pm 0.58$ & $3.53 \pm 0.58$ & $3.53 \pm 0.58$ & $<0.01$ \\
\hline Smoking & $3,878(30.87)$ & $6,438(22.67)$ & $10,316(25.24)$ & $<0.01$ \\
\hline Alcohol/drug use & $2,052(16.53)$ & $4,046(14.11)$ & $6,098(14.87)$ & $<0.01$ \\
\hline Having a mentor & 11,551 (87.89) & $28,863(91.37)$ & 40,414 (90.28) & $<0.01$ \\
\hline \multicolumn{5}{|l|}{ Family function } \\
\hline Family activity (frequency) & $7.03 \pm 2.50$ & $6.73 \pm 2.58$ & $6.84 \pm 2.56$ & $<0.01$ \\
\hline Parent and child relationship $\left(^{\circ}\right)$ & $3.63 \pm 0.59$ & $3.62 \pm 0.62$ & $3.62 \pm 0.61$ & 0.53 \\
\hline No. family members aged $<18 \mathrm{yr}$ & $2.24 \pm 0.97$ & $2.25 \pm 1.00$ & $2.27 \pm 0.99$ & 0.73 \\
\hline Federal poverty level & & & & $<0.01$ \\
\hline $0 \%-99 \%$ & $2,445(26.25)$ & $3,103(14.82)$ & $5,548(18.40)$ & \\
\hline $100 \%-199 \%$ & $2,663(25.03)$ & $4,764(19.23)$ & $7,427(21.05)$ & \\
\hline $200 \%-399 \%$ & $3,889(27.13)$ & $9,854(30.72)$ & $13,743(29.60)$ & \\
\hline$\geq 400 \%$ & $3,791(21.59)$ & $13,355(35.23)$ & $17,146(30.96)$ & \\
\hline \multicolumn{5}{|l|}{ Environmental characteristics } \\
\hline Single-mother & $2,691(24.86)$ & 4,391 (17.18) & 7,082 (19.58) & $<0.01$ \\
\hline Social capital $\left({ }^{\circ}\right)$ & $13.08 \pm 3.11$ & $13.76 \pm 2.77$ & $13.50 \pm 2.94$ & $<0.01$ \\
\hline Neighborhood amenities (frequency) & $2.22 \pm 0.95$ & $2.30 \pm 0.96$ & $2.26 \pm 0.96$ & $<0.01$ \\
\hline Perceived safety (frequency) & $6.73 \pm 1.34$ & $6.92 \pm 1.32$ & $6.86 \pm 1.34$ & $<0.01$ \\
\hline
\end{tabular}

Values are presented as mean \pm standard deviation or number $(\%)$. Data source: 2011-2012 National Survey of Children's Health.

aged $<18$ years $(P=0.73)$ was not significantly related to children's weight.

Lastly, children with a single parent were more overweight than those from other family structures $(P<0.01)$. Nonoverweight children were likely to have more social capital and neighborhood amenities $(P<0.01)$ and to live in safe living conditions $(P<0.01)$ than overweight children. In addition, children living near more reliable, stable, and dependable neighbors were less likely to be over- weight than those who did not.

\section{A sequential multivariable logistic regression analysis of children's weight}

All sequential logistic regression models with covariates (e.g., individual, parent, family, and environment factors) for flourishing were significant $(P<0.01)$ based on our conceptual framework. The odds ratios (ORs) and 95\% CI are shown in Table 2. 
Table 2. Sequential logistic regression analysis of children's weight with covariates (weighted $n=33,293,823$ )

\begin{tabular}{|c|c|c|c|c|c|c|c|c|}
\hline \multirow{2}{*}{ Covariate } & \multicolumn{2}{|c|}{ Individual factors } & \multicolumn{2}{|c|}{ Parenting capacity } & \multicolumn{2}{|c|}{ Family function } & \multicolumn{2}{|c|}{ Environmental characteristics } \\
\hline & $\mathrm{OR}$ & $95 \% \mathrm{Cl}$ & $\mathrm{OR}$ & $95 \% \mathrm{Cl}$ & $\mathrm{OR}$ & $95 \% \mathrm{Cl}$ & $\mathrm{OR}$ & $95 \% \mathrm{Cl}$ \\
\hline \multicolumn{9}{|l|}{ Individual } \\
\hline Age (yr) & 0.90 & (0.78-1.04) & 0.91 & (0.79-1.06) & 0.93 & (0.81-1.08) & 0.93 & $(0.81-1.08)$ \\
\hline Female sex & 1.46 & $(0.76-2.83)$ & 1.50 & $(0.76-2.97)$ & 1.53 & $(0.77-3.03)$ & 1.52 & $(0.77-3.00)$ \\
\hline \multicolumn{9}{|l|}{ Race/ethnicity } \\
\hline Non-Hispanic White & - & & - & & - & & - & \\
\hline Non-Hispanic Black & 0.64 & (0.30-1.38) & 0.67 & (0.29-1.51) & 0.64 & (0.28-1.44) & 0.65 & $(0.28-1.50)$ \\
\hline Hispanic & $0.23^{* *}$ & $(0.09-0.62)$ & $0.20^{* *}$ & $(0.07-0.52)$ & $0.20^{* *}$ & $(0.08-0.54)$ & $0.22^{* *}$ & $(0.08-0.59)$ \\
\hline Other & 1.31 & $(0.45-3.78)$ & 0.95 & (0.31-2.88) & 1.03 & $(0.34-3.10)$ & 1.05 & $(0.35-3.22)$ \\
\hline After school activity & $0.84^{* *}$ & $(0.79-0.89)$ & $0.88^{* *}$ & $(0.82-0.94)$ & $0.92^{*}$ & $(0.86-0.99)$ & $0.92^{*}$ & $(0.86-0.99)$ \\
\hline School missing & $1.02^{* *}$ & (1.01-1.03) & $1.02^{* *}$ & (1.01-1.03) & $1.02^{* *}$ & $(1.01-1.03)$ & $1.02^{* *}$ & $(1.01-1.03)$ \\
\hline Sleep enough & 0.98 & $(0.95-1.02)$ & 0.99 & (0.96-1.02) & 0.98 & $(0.94-1.01)$ & 0.97 & $(0.94-1.00)$ \\
\hline Physical activity & $0.95^{* *}$ & (0.93-0.98) & $0.95^{* *}$ & (0.93-0.98) & $0.95^{* *}$ & $(0.93-0.97)$ & $0.95^{* *}$ & (0.93-0.98) \\
\hline Sedentary behavior & $1.03^{* *}$ & $(1.01-1.04)$ & $1.02^{*}$ & $(1.00-1.04)$ & 1.02 & $(1.00-1.03)$ & 1.02 & $(1.00-1.04)$ \\
\hline Flourishing & 0.86 & $(0.52-1.41)$ & 0.89 & $(0.54-1.47)$ & 0.89 & $(0.54-1.47)$ & 0.90 & $(0.55-1.48)$ \\
\hline Flourishing *age & 0.99 & $(0.96-1.02)$ & 0.99 & (0.95-1.02) & 0.99 & (0.95-1.02) & 0.99 & $(0.95-1.02)$ \\
\hline Flourishing ${ }^{*}$ female & $0.84^{*}$ & $(0.72-0.98)$ & $0.83^{*}$ & $(0.71-0.98)$ & $0.83^{*}$ & $(0.70-0.97)$ & $0.83^{*}$ & $(0.70-0.97)$ \\
\hline \multicolumn{9}{|l|}{ Flourishing *race/ethnicity } \\
\hline Non-Hispanic White & - & & - & & - & & - & \\
\hline Non-Hispanic Black & $1.31^{* *}$ & (1.09-1.58) & $1.26^{*}$ & $(1.04-1.54)$ & $1.25^{*}$ & $(1.03-1.53)$ & $1.25^{*}$ & $(1.02-1.52)$ \\
\hline Hispanic & $1.63^{* *}$ & $(1.29-2.06)$ & $1.66^{* *}$ & $(1.31-2.10)$ & $1.61^{* *}$ & $(1.27-2.03)$ & $1.56^{* *}$ & $(1.24-1.96)$ \\
\hline Other & 0.97 & $(0.75-1.25)$ & 1.04 & (0.79-1.36) & 1.01 & $(0.77-1.32)$ & 1.00 & $(0.77-1.32)$ \\
\hline \multicolumn{9}{|l|}{ Parenting capacity } \\
\hline Parents' health & & & $0.92^{* *}$ & $(0.90-0.94)$ & $0.95^{* *}$ & (0.93-0.98) & $0.94^{* *}$ & $(0.91-0.98)$ \\
\hline Parents' involvement & & & 0.99 & (0.96-1.02) & 0.99 & $(0.96-1.02)$ & 0.99 & (0.96-1.02) \\
\hline Parents' stress coping & & & 1.06 & (0.96-1.18) & 1.02 & (0.90-1.11) & 1.02 & (0.92-1.13) \\
\hline Smoking & & & $1.34^{* *}$ & (1.19-1.51) & $1.26^{* *}$ & $(1.12-1.43)$ & $1.25^{* *}$ & $(1.10-1.41)$ \\
\hline Alcohol/drug use & & & 0.95 & (0.80-1.11) & 0.95 & (0.81-1.12) & 0.93 & $(0.79-1.10)$ \\
\hline Having a mentor & & & 0.91 & $(0.74-1.14)$ & 0.94 & (0.77-1.18) & 1.02 & $(0.79-1.26)$ \\
\hline \multicolumn{9}{|l|}{ Family function } \\
\hline Family activity & & & & & $1.05^{* *}$ & $(1.02-1.07)$ & $1.05^{* *}$ & $(1.02-1.07)$ \\
\hline Parent-child relationship & & & & & 1.10 & (0.99-1.22) & $1.11^{*}$ & $(0.99-1.23)$ \\
\hline No. family members aged $<18 \mathrm{yr}$ & & & & & $0.89^{* *}$ & $(0.84-0.95)$ & $0.90^{* *}$ & $(0.85-0.96)$ \\
\hline \multicolumn{9}{|l|}{ Federal poverty level } \\
\hline $0 \%-99 \%$ & & & & & - & & - & \\
\hline $100 \%-199 \%$ & & & & & $0.82^{*}$ & $(0.68-0.98)$ & $0.81^{*}$ & $(0.68-0.98)$ \\
\hline $200 \%-399 \%$ & & & & & $0.66^{* *}$ & $(0.55-0.79)$ & $0.66^{* *}$ & $(0.56-0.79)$ \\
\hline$\geq 400 \%$ & & & & & $0.52^{* *}$ & $(0.43-0.63)$ & $0.54^{* *}$ & $(0.44-0.65)$ \\
\hline \multicolumn{9}{|l|}{ Environmental characteristics } \\
\hline Single parent & & & & & & & 0.86 & $(0.71-1.04)$ \\
\hline Neighborhood amenities & & & & & & & 0.96 & (0.91-1.01) \\
\hline Social capital & & & & & & & $0.97^{*}$ & $(0.95-0.99)$ \\
\hline Perceived safety & & & & & & & 0.99 & (0.94-1.03) \\
\hline Wald tests & & & \multicolumn{2}{|c|}{$F(6,90)^{* *}=12.39(P<0.01)$} & \multicolumn{2}{|c|}{$F(6,90)^{* *}=13.23(P<0.01)$} & \multicolumn{2}{|c|}{$F(4,90)^{* *}=3.48(P<0.01)$} \\
\hline
\end{tabular}

$\mathrm{OR}$, odds ratio; $\mathrm{Cl}$, confidence interval.

${ }^{*} P<0.05$. ${ }^{* *} P<0.01$.

Data source: 2011-2012 National Survey of Children's Health. 
Ten independent variables associated with children's weight had significantly different OR in their binary BMI levels (i.e., overweight $[\geq 85$ th percentile] vs. healthy weight $[<85$ th percentile $]$ ).

First, Hispanic American children were $78 \%$ less likely to be overweight compared to non-Hispanic White children. Second, a 1-unit (1 day) increase of after-school activity and physical activity decreased the odds of being overweight. Third, a 1-unit (1 day) increase of school days missed increased the odds of being overweight.

Regarding parenting capacity resources, two independent variables were significantly predicted children's depression such as parents' health, involvement, stress coping, and alcohol/drug use (all $P<0.01$ ). Increases in parents' health, decreased the odds of children being overweight. In addition, children whose parents smoked were more likely to be overweight than those who did not smoke.

Regarding family function, four independent factors were significant predictors of children's overweight: family activity, parent and child relationship, number of family members aged $<18$ years, and income level (all $P<0.01$ ). Increased family activity and children who had a better relationship with their parents were more likely to be overweight than their counterparts. An increase in the number of family members aged $<18$ years decreased the risk of children being overweight. Lastly, children from lower-income families were more likely to be overweight than those from middle- or high-income homes.

Additionally, to determine if age, sex, and race/ethnicity moderated any of these effects of flourishing or being overweight, this study used the product of coefficients procedure (Aiken et al., 1991). Specifically, I re-ran the regression model with age, sex, and race/ethnicity entered into the analysis with flourishing after controlling for other socioecological factors. The sex and race/ethnicity product term was significant $(P<0.05)$, indicating that sex and race/ethnicity did act as moderators. Specially, girls with higher flourishing scores were $17 \%$ less likely to be overweight compared to that of nonflourished boys. Regarding flourishing and race/ethnicity, compared to the odds of being overweight among non-Hispanic White participants, non-Hispanic Black participants and Hispanic participants were more likely to be overweight (Table 2).

\section{DISCUSSION}

This study examined how children's flourishing contributes to their likelihood of being overweight after controlling for socioeco- logical determinants. In addition, this study sought to determine whether age, sex, and race/ethnicity moderated this relationship among children aged 10-17 years from a large, nationally representative, nonclinical sample.

Children's flourishing was not a fully significant predictor of children's weight. This is partially because flourishing refers to happiness and emotional well-being (De Ruyter, 2007; Seligman, 2011), which can be achieved by positive emotions, relationships, engagement, a meaningful purpose, and accomplishment in accordance with overcoming one's hardships, adversity, and trauma, and volunteering. It seems to not directly affect children's physical health, like obesity status, unlike poor lifestyle habits such as a lack of physical activity and sedentary lifestyles (Benjamin, 2010). However, children's negative emotions (e.g., depression, sadness, and hopelessness) affect their likelihood of obesity; an increased sense of sadness and hopelessness may result in increased weight gain (Goodman and Whitaker, 2002). Therefore, further research needs to pay more attention to whether children's flourishing is directly associated with their weight.

However, sex and race/ethnicity differences were significant moderators of children's flourishing as seen in children's weight when controlling for socioecological factors. Girls who flourished were less likely to be overweight than boys. Females going through puberty were more likely than males to be sensitive and easily affected by external factors and their environments (Belsky et al., 1991). Therefore, there may be a link between girls' flourishing, weight, and developmental sex characteristics. Moreover, there were race/ethnicity differences in flourishing and weight. Flourishing non-Hispanic Black and Hispanic children were more likely to be obese than were non-Hispanic White children. This finding is consistent with race/ethnicity disparities in the prevalence of obesity among U.S. children: Mexican and Black children are more likely to be obese than are White children (Ogden et al., 2012).

Poor lifestyle patterns, including a lack of physical activity and living a sedentary lifestyle (Benjamin, 2010), are associated with obesity and are attributed to family (Gibson et al., 2013), school (Williams et al., 2013), community (Bleich et al., 2013), and environmental (Zhao and Settles, 2014) factors. These risk factors of children's weight gain were consistent with previous research (Boonpleng et al., 2013). Therefore, comprehensive and multileveled approaches are needed to address the behavioral and environmental risk factors associated with children's obesity, which could lead to more effective behavioral and policy interventions across diverse settings (e.g., family, school, district, and state) (Must et 
al., 2014).

Regarding parenting capacity, parents' health, and specific health-risk behaviors (e.g., smoking) were significant predictors of being overweight. This study showed that parents' health status and risky behaviors (i.e., smoking) were associated with their children's weight. This is consistent with a previous study that parents' or guardians' smoking status negatively impacted their children's weight (Wade et al., 2014). Parents' influence on children's obesity in many studies was also confirmed such as praising children about their health choices (Wrotniak et al., 2005), parenting styles and orientations (Stein et al., 2005), and parent health-risk behaviors (Wickrama et al., 1999).

Children having affluent parents were less likely to be overweight compared with those from nonaffluent families. Possible explanations include that wealthy parents may have more time to accompany their children and may be more likely to have no financial issues and can help their children participate in diverse activities. Having more family members aged younger than 18 years was associated with lower odds of being overweight in children, which is consistent with a study by Gonzalez-Casanova et al. (2014). However, unlike studies by Davison et al. (2013) and Grossklaus and Marvicsin (2014), children who participate in more family activities (e.g., attendance of a religious service and meal together) and who have a better relationship with their parents were more likely to be overweight than their counterparts. A more favorable and happier family environment does not seem to diminish childhood obesity.

Children who had neighbors who were willing to help and watch other children in the community were less likely to be overweight (Evans and Kutcher, 2011). This is evidence that children living with more reliable and trustworthy neighbors are more likely to go out to play and interact with them and their children in the community, thus making them more active and less sedentary. Children with a single parent, however, were less likely to be overweight compared with those from a non-single parent family (although not statistically significant). Possible explanations include that single parents may pay more attention to their children's health and nutrition. This study also found that neighborhood amenities were not significantly associated with children's weight status such as existing sidewalks, walking paths, parks, playground areas, or a recreation and community center in their area.

Other meaningful findings were also reported including how individual factors affect children's weight including missed school days, the level of physical activity, sedentary lifestyles, etc. Partici- pating in after school activities and being physical active were also significant predictors of children's weight, which is consistent with previous studies (Millar et al., 2013). Missing school negatively influenced children's likelihood of being overweight (Li et al., 2012)

Must et al. (2014) showed that family, school, and the community play a key role in preventing or minimizing children's obesity; especially, by establishing healthy and positive environments with polices and initiatives that can provide opportunities for children to learn, practice healthy eating, and become more physically active.

In conclusion, an understanding of flourishing and the role of family, school, and the community regarding how and what contribute to children's obesity is vital to prevent and minimize this dangerous pandemic of obesity.

\section{CONFLICT OF INTEREST}

No potential conflict of interest relevant to this article was reported.

\section{REFERENCES}

Aiken LS, West SG, Reno RR. Multiple regression: testing and interpreting interactions: Thousand Oaks (CA): Sage; 1991.

Belsky J, Steinberg L, Draper P. Childhood experience, interpersonal development, and reproductive strategy: and evolutionary theory of socialization. Child Dev 1991;62:647-670.

Benjamin RM. The Surgeon General's vision for a healthy and fit nation. Public Health Rep 2010;125:514-515.

Bleich SN, Segal J, Wu Y, Wilson R, Wang Y. Systematic review of community-based childhood obesity prevention studies. Pediatrics 2013; 132:e201-210.

Blumberg SJ, Olson L, Frankel M, Osborn L, Becker CJ, Srinath KP, Giambo P. Design and operation of the National Survey of Children with Special Health Care Needs, 2001. Vital Health Stat 1 2003;(41):1-136.

Boonpleng W, Park CG, Gallo AM, Corte C, McCreary L, Bergren MD. Ecological influences of early childhood obesity: a multilevel analysis. West J Nurs Res 2013;35:742-759.

Bronfenbrenner U. Ecological models of human development. In: Husén T, Postlethwaite TN, editors. The international encyclopedia of education. Oxford: Pergamon; 1994. p. 1643-1647.

Centers for Disease Control and Prevention. Healthy weight. About child \& teen BMI. What is a BMI percentile and how is it interpreted? [Internet]. Atlanta (GA): Centers for Disease Control and Prevention; 2009 
[cited 2016 Jun 22]. Available from: http://www.cdc.gov/healthyweight/assessing/bmi/childrens_bmi/about_childrens_bmi.html.

Centers for Disease Control and Prevention. National center for health statistics. State and local area integrated telephone survey. 2011-2012 National survey of children's health [Internet]. Atlanta (GA): Centers for Disease Control and Prevention; 2013 [cited 2017 Jul 15]. Available from: http://www.cdc.gov/nchs/slaits/nsch.htm.

Cleaver H, Walker S. From policy to practice: the implementation of a new framework for social work assessments of children and families. Child Fam Soc Work 2004;9:81-90.

Davison KK, Birch LL. Childhood overweight: a contextual model and recommendations for future research. Obes Rev 2001;2:159-171.

Davison KK, Jurkowski JM, Li K, Kranz S, Lawson HA. A childhood obesity intervention developed by families for families: results from a pilot study. Int J Behav Nutr Phys Act 2013;10:3.

De Ruyter D. Ideals, education, and happy flourishing. Educ Theory 2007; 57:23-35.

Evans GW, Kutcher R. Loosening the link between childhood poverty and adolescent smoking and obesity: the protective effects of social capital. Psychol Sci 2011;22:3-7.

Gibson LY, Allen KL, Byrne SM, Davis L, Zubrick SR. The role of family and maternal factors in the development and maintenance of childhood obesity. Obes Res Clin Pract 2013;7:e118-119.

Gonzalez-Casanova I, Sarmiento OL, Pratt M, Gazmararian JA, Martorell R, Cunningham SA, Stein A. Individual, family, and community predictors of overweight and obesity among colombian children and adolescents. Prev Chronic Dis 2014;11:E134.

Goodman E, Whitaker RC. A prospective study of the role of depression in the development and persistence of adolescent obesity. Pediatrics 2002;110:497-504.

Grossklaus H, Marvicsin D. Parenting efficacy and its relationship to the prevention of childhood obesity. Pediatr Nurs 2014;40:69-86.

Guo SS, Chumlea WC. Tracking of body mass index in children in relation to overweight in adulthood. Am J Clin Nutr 1999;70:145S-148S.

Krebs NF, Himes JH, Jacobson D, Nicklas TA, Guilday P, Styne D. Assessment of child and adolescent overweight and obesity. Pediatrics 2007;120(Suppl 4):S193-228.

Li C, Ford ES, Zhao G, Mokdad AH. Prevalence of pre-diabetes and its association with clustering of cardiometabolic risk factors and hyperinsulinemia among U.S. adolescents: National Health and Nutrition Examination Survey 2005-2006. Diabetes Care 2009;32:342-347.

Li Y, Raychowdhury S, Tedders SH, Lyn R, Lòpez-De Fede A, Zhang J. Association between increased BMI and severe school absenteeism among US children and adolescents: findings from a national survey, 2005-2008. Int J Obes (Lond) 2012;36:517-523.

Millar L, Robertson N, Allender S, Nichols M, Bennett C, Swinburn B. Increasing community capacity and decreasing prevalence of overweight and obesity in a community based intervention among Australian adolescents. Prev Med 2013;56:379-384.

Must A, Curtin C, Hubbard K, Sikich L, Bedford J, Bandini L. Obesity prevention for children with developmental disabilities. Curr Obes Rep 2014;3:156-170.

Ogden CL, Carroll MD, Kit BK, Flegal KM. Prevalence of childhood and adult obesity in the United States, 2011-2012. JAMA 2014;311:806-814.

Ogden CL, Carroll MD, Kit BK, Flegal KM. Prevalence of obesity and trends in body mass index among US children and adolescents, 19992010. JAMA 2012;307:483-490.

Russell-Mayhew S, McVey G, Bardick A, Ireland A. Mental health, wellness, and childhood overweight/obesity. J Obes 2012;2012:281801.

Seligman ME. Flourish: a visionary new understanding of happiness and well-being. New York: Free Press; 2011.

Stein RI, Epstein LH, Raynor HA, Kilanowski CK, Paluch RA. The influence of parenting change on pediatric weight control. Obes Res 2005; 13:1749-1755.

U.S. Department of Health \& Human Services. Physical activity and fitness. In: U.S. Department of Health \& Human Services. Healthy people. 2nd ed. Washington, DC: U.S. Government Printing Office; 2010.

Wade KH, Skugarevsky O, Kramer MS, Patel R, Bogdanovich N, Vilchuck K, Sergeichick N, Richmond R, Palmer T, Smith GD, Gillman M, Oken E, Martin RM. Prospective associations of parental smoking, alcohol use, marital status, maternal satisfaction, and parental and childhood body mass index at 6.5 years with later problematic eating attitudes. Nutr Diabetes 2014;4:e100.

Wickrama KA, Conger RD, Wallace LE, Elder GH Jr. The intergenerational transmission of health-risk behaviors: adolescent lifestyles and gender moderating effects. J Health Soc Behav 1999;40:258-272.

Williams AJ, Henley WE, Williams CA, Hurst AJ, Logan S, Wyatt KM. Systematic review and meta-analysis of the association between childhood overweight and obesity and primary school diet and physical activity policies. Int J Behav Nutr Phys Act 2013;10:101.

Wrotniak BH, Epstein LH, Paluch RA, Roemmich JN. The relationship between parent and child self-reported adherence and weight loss. Obes Res 2005;13:1089-1096.

Zhao J, Settles BH. Environmental correlates of children's physical activity and obesity. Am J Health Behav 2014;38:124-133. 